\title{
Experimental calibration of parallel-to-grain strain penetration length for internal epoxied bars
}

\author{
Francesco Sarti ${ }^{1}$, Alessandro Palermo ${ }^{2}$ and Stefano Pampanin ${ }^{3}$
}

\begin{abstract}
Tensile strain penetration effects have been first investigated in the study of reinforced concrete components as experimental studies highlighted that theoretical values for the equivalent plastic hinge length did not reflect the observed experimental results. This is due to the elongation of the bars beyond the theoretical interface of the structural element with another component (e.g. beam-to-column or column/wall-to-foundation connections). The concept of an equivalent strain penetration length was first introduced for flexural analysis of concrete elements and the definition of the element's plastic hinge length.
\end{abstract}

Experimentally calibrated expressions for the equivalent strain penetration length have been developed in literature and extensively adopted in the design of traditional reinforced concrete connections.

Internal partially unbonded bars have more recently been used is precast concrete dissipative posttensioned rocking systems, developed during the PREcast Seismic Structural Systems (PRESSS) program, and more recently in timber rocking (Pres-Lam)

As per bars embedded or post-grouted into concrete, internally glued bars in timber are affected by tensile strain penetration effects. An important parameter involved in the design of dissipative rocking section as well as more traditional epoxied rods connections is the additional slip and consequent loss of stiffness, strength and energy dissipation due to strain penetration.

The paper shows the determination of an equivalent strain penetration length in internal epoxied bars through the experimental testing of several specimens accounting for different geometric parameters. The final part of the paper discussed the experimental results in terms of bar slip proposing simplified analytical formulas.

KEYWORDS: timber connections, seismic design, Pres-Lam, post-tensioning

\section{Introduction}

The concept of an equivalent strain penetration length was first introduced for flexural analysis of concrete elements and the definition of the element's plastic hinge length. Theoretical values for the equivalent plastic hinge length based on integration of the curvature distribution for typical members

\footnotetext{
${ }^{1}$ Structural Timber Research Engineer, Civil and Natural Resources Engineering Department, University of Canterbury, Christchurch

${ }^{2}$ Associate Professor, Civil and Natural Resources Engineering Department, University of Canterbury, Christchurch

${ }^{3}$ Professor, Civil and Natural Resources Engineering Department, University of Canterbury, Christchurch
} 
would make such length directly proportional to the total length of the element. Such values do not, however, agree well with experimentally measured lengths. This is because the theoretical curvature distribution ends abruptly at the base of the cantilever, while steel tensile strains continue, due to the development of bond stress, for some depth into the footing. The elongation of bars beyond the theoretical base leads to additional rotation and deflection in global terms, and to a lower strain demand on the reinforcing bars, thus affecting the achievement of targeted strength and energy dissipation capacity. The phenomenon is referred to as tensile strain penetration [1].

Based on experimental research carried out by Sritharan [2] Equation (1) reports the calibrated equivalent strain penetration length for bonded steel reinforcing bars.

$l_{s p}=0.022 f_{y} d_{b}$

Where $\mathrm{f}_{\mathrm{y}}$ is the bar's tensile strength and $\mathrm{d}_{\mathrm{b}}$ the bar diameter.

This calibrated analytical model has been widely adopted in literature for the design of reinforced concrete elements $[1,3]$

Grouted bars have also been extensively used in post-tensioned rocking elements developed during the PREcast Seismic Structural Systems Program (PRESSS) [4] and the analytical formula in Equation (1) was adopted to estimate the strain in partially unbonded bars used as dissipative source. In PRESSS systems internal bars are used in combination to unbonded post-tensioning tendons providing a combination of dissipation and re-centering capabilities.

In more recent years, the PRESSS system concept has been extended to structural steel elements [5] and Laminated Veneer Lumber elements (Pres-Lam systems) [6].

In Pres-Lam elements, similarly to PRESSS systems, internal epoxied bars have been used as dissipative reinforcement (Figure 1a).
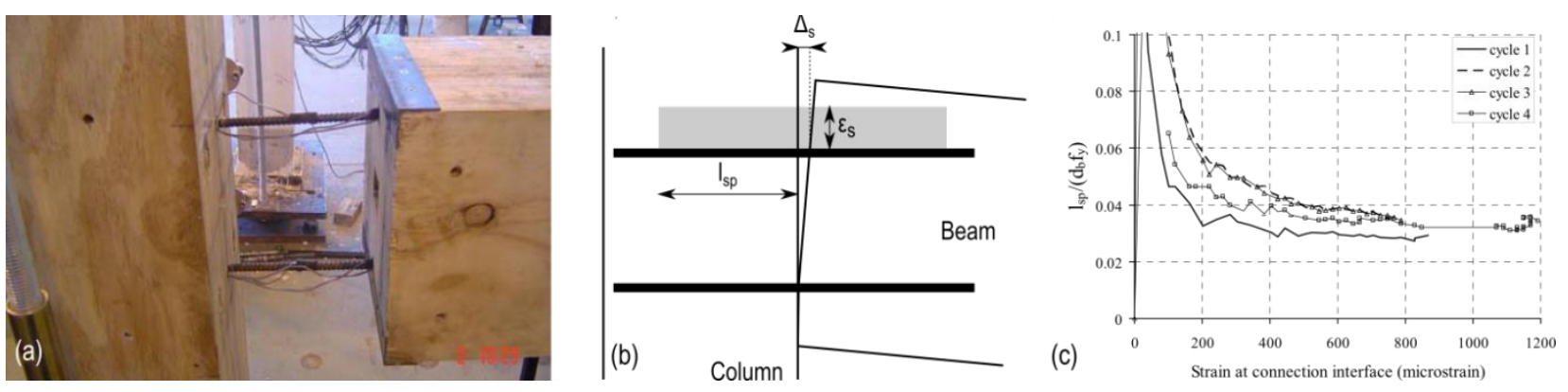

Figure 1.(a) Beam-column subassembly with internal bars; (b) assumed strain distribution for fully bonded energy dissipation system; (c) Average normalised strain penetration length assuming a uniform strain distribution within the bonded region for a beam-column connection vs. versus drift (modified from Newcombe et al. [7]).

\subsection{Literature review of basic techniques}

Extensive experimental research on the behaviour of epoxied connections in timber have been carried out by Buchanan and Fairweather [8] and Buchanan [9] proving the high damping capabilities of such 
connections. Design provisions for epoxied bar in glulam and Laminated Veneer Lumber (LVL) have been provided by experimental research by Buchanan [10].

Whilst this research had been focusing on the strength of such connection type, limited research has been carried out on its stiffness.

A tentative derivation of an approximate strain penetration length for mild steel bars epoxied in timber elements was carried out by Newcombe et al. [7] as part of an experimental campaign on post-tensioned timber beam-column subassemblies. Fully bonded epoxied bars were used as internal energy dissipation mechanism. Three strain gauges were placed along the internal bars/dissipaters in an attempt to measure the extent of the strain penetration (Figure 1a). In the behavior of a beam-column rocking connection with fully bonded internal rebars it could be assumed that all the deformation is due to strain penetration. The latter was then inferred by assuming a constant strain profile over the strain penetration length as shown in Figure $1 b$.

As shown in Figure 1c it was noted that the strain penetration length converged to an asymptote as the deformation increased. The average asymptotic value was approximately $130 \mathrm{~mm}$ (or $0.032 \mathrm{f}_{\mathrm{y}} \mathrm{d}_{\mathrm{b}}$ if it assumed that the strain penetration length is related to yield strength and bar diameter as it is for cement grout) [7]:

$$
l_{s p}=0.032 f_{y} d_{b}[\mathrm{~mm}]
$$

Where $\mathrm{f}_{\mathrm{y}}$ is the yield strength of the bar (MPa) and $\mathrm{d}_{\mathrm{b}}$ the bar diameter $(\mathrm{mm})$.

Therefore, for fully bonded energy dissipation system the maximum strain, $\varepsilon_{\mathrm{s}}$, at the connection interface can be approximated as:

$\varepsilon_{s}=\frac{\Delta_{s}}{2 l_{s p}}=\frac{\Delta_{s}}{0.064 f_{y} d_{b}}$

Where $\Delta_{\mathrm{s}}$ is the bar displacement from gap opening (see Figure 1b)

It is to be clarified that the average strain penetration length above is only valid for beam-column joints, where both parallel and perpendicular to the grain contributions are present. Newcombe et al. [7] observed from experimental results that the strain within the beam (i.e. parallel to the grain) is approximately $40 \%$ of the total [7]; therefore, the strain penetration parallel to the grain can be calculated as:

$l_{s p, p a r a}=0.024 f_{y} d_{b}$

The research presented in this paper aims to provide a more comprehensive experimental calibration of the parallel-to-grain strain penetration formulation based on more rigorous measurement of the strain distribution in the bond area, with possible application to wall-foundation, column-foundation or timber beam-concrete column connections.

The paper firstly discusses the methodology of the experimental campaign which involved the testing of different bar geometries as well as steel grade. 
A crucial aspect of this research was the data analysis method necessary to infer significant design parameters from the recorded experimental data. A detailed discussion on the differential equation approach is provided in the paper.

The final part of the paper presents the proposed analytical model for the determination of parallel-tograin strain penetration effects and provides a simple section analysis example.

\section{Test methodology}

\subsection{Testing schedule}

To provide a comprehensive set of specimens, different bar types and geometric properties were considered in the experimental campaign. Both threaded and deformed bars were used, in particular M16, M20 and M24 (SP16t, SP20t and SP24t in Table 1) threaded bars and 20mm and 25mm diameter deformed bars were tested. The testing schedule is summarized in Table 1, which also reports the significant geometric properties of the specimens with reference to Figure 2.

Two main sets of specimens for each geometry were tested. At first, monotonic tests were carried out; cyclic tests were then performed to assess whether degradation in the bond behaviour occurs.

The specimen section in Table 1 was governed by the minimum edge distance according to Buchanan [10] and also by standard profiles provided by the manufacturers.

A set of specimens were also designed to create a pull-out failure (Bond specimens in Table 1), so a shorter embedment length of $80 \mathrm{~mm}$ was provided.

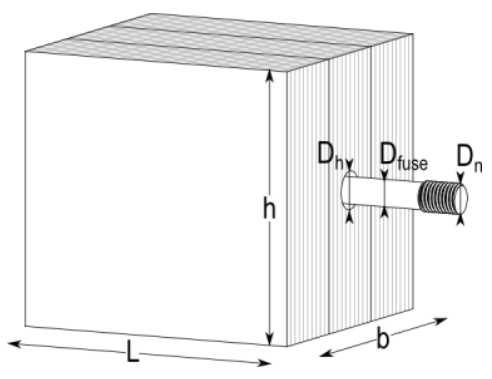

Figure 2. Specimen geometry
Table 1. Testing schedule

\begin{tabular}{|c|c|c|c|c|c|c|}
\hline ID & $\begin{array}{l}\text { Nom. Diam. } \\
\left(D_{n}\right) \\
(\mathrm{mm})\end{array}$ & $\begin{array}{l}\text { Hole Diam. } \\
\left(D_{\mathrm{h}}\right) \\
(\mathrm{mm})\end{array}$ & $\begin{array}{l}\text { Spec. Length } \\
\text { (L) } \\
(\mathrm{mm})\end{array}$ & $\begin{array}{l}\text { Spec. Section } \\
(\mathrm{b} \times \mathrm{h}) \\
(\mathrm{mm})\end{array}$ & $\begin{array}{l}\text { Fuse } \\
\text { Diam. } \\
\left(D_{\text {fuse }}\right) \\
(\mathrm{mm})\end{array}$ & $\begin{array}{l}\text { Strain } \\
\text { Gauge } \\
\text { Spacing } \\
(\mathrm{mm})\end{array}$ \\
\hline Bond & 16 & 20 & 80 & $135 \times 140$ & $\mathrm{n} / \mathrm{a}$ & $\mathrm{n} / \mathrm{a}$ \\
\hline SP16t & 16 & 20 & 290 & $135 \times 140$ & 14 & 25 \\
\hline SP20t & 20 & 26 & 370 & $135 \times 140$ & 16 & 30 \\
\hline SP24t & 24 & 30 & 550 & $180 \times 190$ & 20 & 35 \\
\hline SP20d & 20 & 26 & 550 & $135 \times 140$ & 14 & 30 \\
\hline SP25d & 25 & 32 & 800 & $180 \times 190$ & 16 & 35 \\
\hline
\end{tabular}

\subsection{Specimen fabrication}

As anticipated, the experimental program was oriented to calibrate parallel-to-grain strain penetration effects; therefore, only this grain direction was considered in this study.

The specimens were fabricated out of LVL11 standards profiles. To provide the required edge distance, different $63 \mathrm{~mm}$ thick panels were glued together and a hole was drilled in the centre of the section allowing the bar to be inserted and glued. A hole was drilled at the bottom side of the specimen, allowing an optimal injection of the epoxy from the bottom up (Figure 3a). 


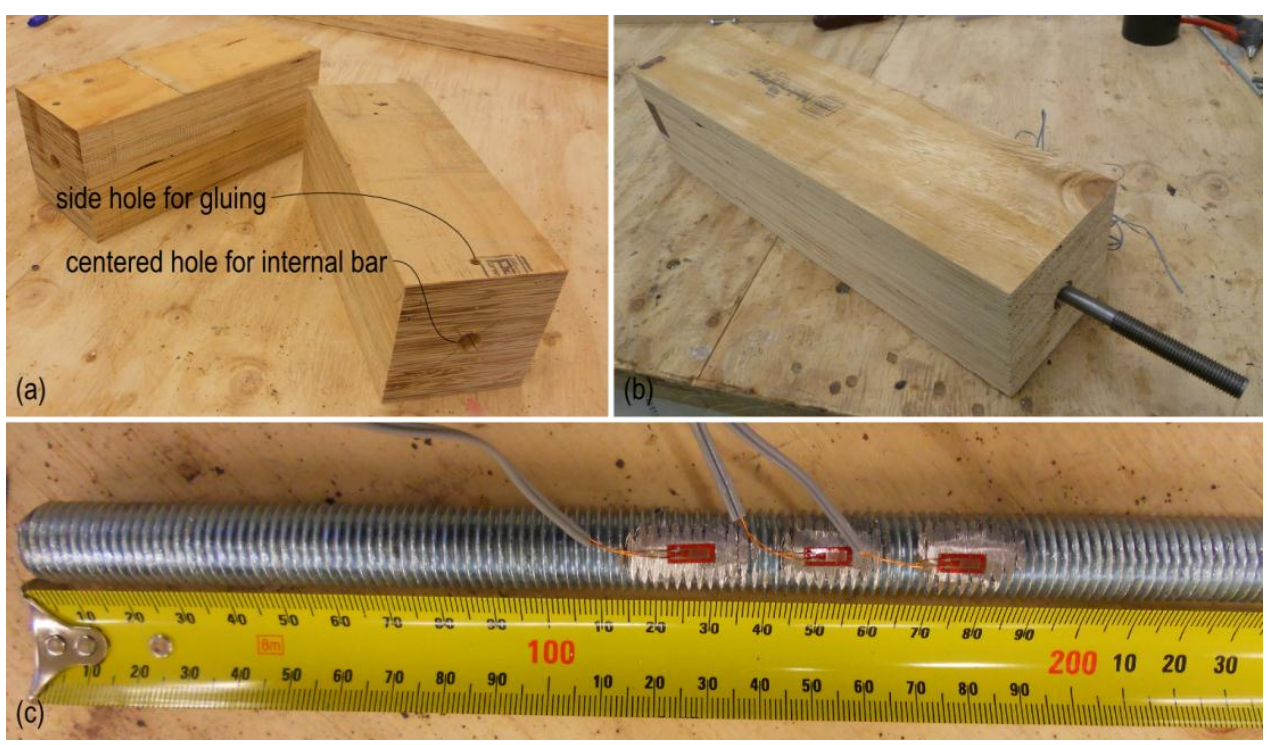

Figure 3. Specimen fabrication. (a) Timber block; (b) finished specimen and (c) instrumentation on the internal bar

Before gluing, some machining of the bars was necessary. To attach the specimen to the machine, a threaded end was to be provided. The threaded bar was readily available for threaded bars, yet for reinforcing bars that had to be machined from the deformed bars.

A fuse length was provided in the specimens and the reduced diameter was rounded down from the net diameter of the thread bar.

Instrumentation comprised of strain gauges glued on the bar; consequently, those were part of the fabrication process. To allow the strain gauges to be successfully glued on the bars, some surface preparation was necessary. For deformed bars, the surface had to be slightly sanded to provide an even surface for the instruments. Differently, in the case of threaded bars (see Figure 3c), few threads needed to be grinded. The strain gauges were positioned at even distances in the specimens, using different spacing for each diameter. In particular, a spacing of $25 \mathrm{~mm}, 30 \mathrm{~mm}$ and $35 \mathrm{~mm}$ was chosen for specimens SP16t, SP20t and SP24t respectively and 30mm and 35mm for specimens SP20d and SP25d.

\subsection{Materials}

The timber blocks were fabricated out of LVL11 standard profiles glued using resorcinol glue. The block was then machined to create the space allowing for clearance for the bar positioning. The bars were fixed to the timber element using epoxy resin Hilti HIT-RE500.

Table 2. Material nominal properties.

\begin{tabular}{lll|l|l|l|} 
Property & Value & \multicolumn{2}{c}{ Property } & \multicolumn{1}{c}{ Value } \\
\hline \multicolumn{3}{c}{ Laminated Veneer Lumber } & & \multicolumn{2}{c}{ Reinforcing steel (Grade300E) } \\
\hline Modulus of Elasticity (parallel to grain) & $\mathrm{E}_{\mathrm{t}}$ & $11000 \mathrm{MPa}$ & Yield stress & $\mathrm{f}_{\mathrm{y}}$ & $300 \mathrm{MPa}$ \\
Bending strength & $\mathrm{f}_{\mathrm{bt}}$ & $38 \mathrm{MPa}$ & Ultimate stress & $\mathrm{f}_{\mathrm{u}}$ & $450 \mathrm{MPa}$ \\
Compression strength & $\mathrm{f}_{\mathrm{ct}}$ & $45 \mathrm{MPa}$ & Modulus of Elasticity & $\mathrm{E}_{\mathrm{s}, 300}$ & $200 \mathrm{GPa}$ \\
\hline \multicolumn{2}{c|}{ Epoxy Resin (Hilti HIT-RE500)} & & \multicolumn{2}{c}{ Threaded bar steel $($ Grade 4.6) } \\
\hline Compressive strength & $\mathrm{f}_{\mathrm{c}}$ & $82.7 \mathrm{MPa}$ & Yield stress & $\mathrm{f}_{\mathrm{yp}}$ & $320 \mathrm{MPa}$ \\
Tensile strength & $\mathrm{f}_{\mathrm{t}}$ & $43.5 \mathrm{MPa}$ & Ultimate stress & $\mathrm{f}_{\mathrm{up}}$ & $400 \mathrm{MPa}$ \\
Modulus of Elasticity & $\mathrm{E}_{\mathrm{fill}}$ & $1.493 \mathrm{GPa}$ & Modulus of Elasticity & $\mathrm{E}_{\mathrm{s}, 4.6}$ & $200 \mathrm{GPa}$ \\
\hline
\end{tabular}


Two different steel grades were tested. At first Grade300E reinforcing steel bars were used, but also threaded mild steel bars were used (Grade 4.6). The nominal properties of the aforementioned materials are summarized in Table 2.

\subsection{Test setup and protocol}

A Dartec 10MN Universal Testing Machine (UTM) was used as shown in Figure 4b. The testing machine had a maximum force of $10 \mathrm{MN}$, with a maximum actuator stroke of $300 \mathrm{~mm}$ and maximum and minimum velocities of 16 and $0.002 \mathrm{~mm} / \mathrm{s}$ respectively. For the purposes of the experimental campaign the testing was carried out at $40 \mathrm{~mm} / \mathrm{min}$.

The test setup (Figure 4b) included a set of steel connecting plates. Two plates were connected using 1.5 " bolts to the $1000 \mathrm{kN}$ load cell and the moving head of the machine. The attachment of the specimen to the moving head at the bottom of the test setup comprised of a set of different interchangeable $135 \mathrm{~mm} \times 135 \mathrm{~mm}, 40 \mathrm{~mm}$ thick plates. At the centre of the plate a threaded hole was drilled and tapped.

Four M16 Grade 8.8 bolts connected the smaller plate to the moving head of the machine.

To connect the timber block, two $40 \mathrm{~mm}$ thick plates were bolted to the load cell at the top of the machine using M24 G8.8 threaded bars. The specimen was then clamped between the two plates. Figure 4a shows the 3D view view of the test setup with the indication of the different components.

Experimental testing comprised of both monotonic and cyclic testing. The former was carried out by increasing tensile displacement up to failure of the glued bar.

Since tensile strain penetration effects investigation was targeted, only tension displacement were necessary and a modified regime based on ACI ITG-5.1-07 protocol [11] was used (see Figure 5a).
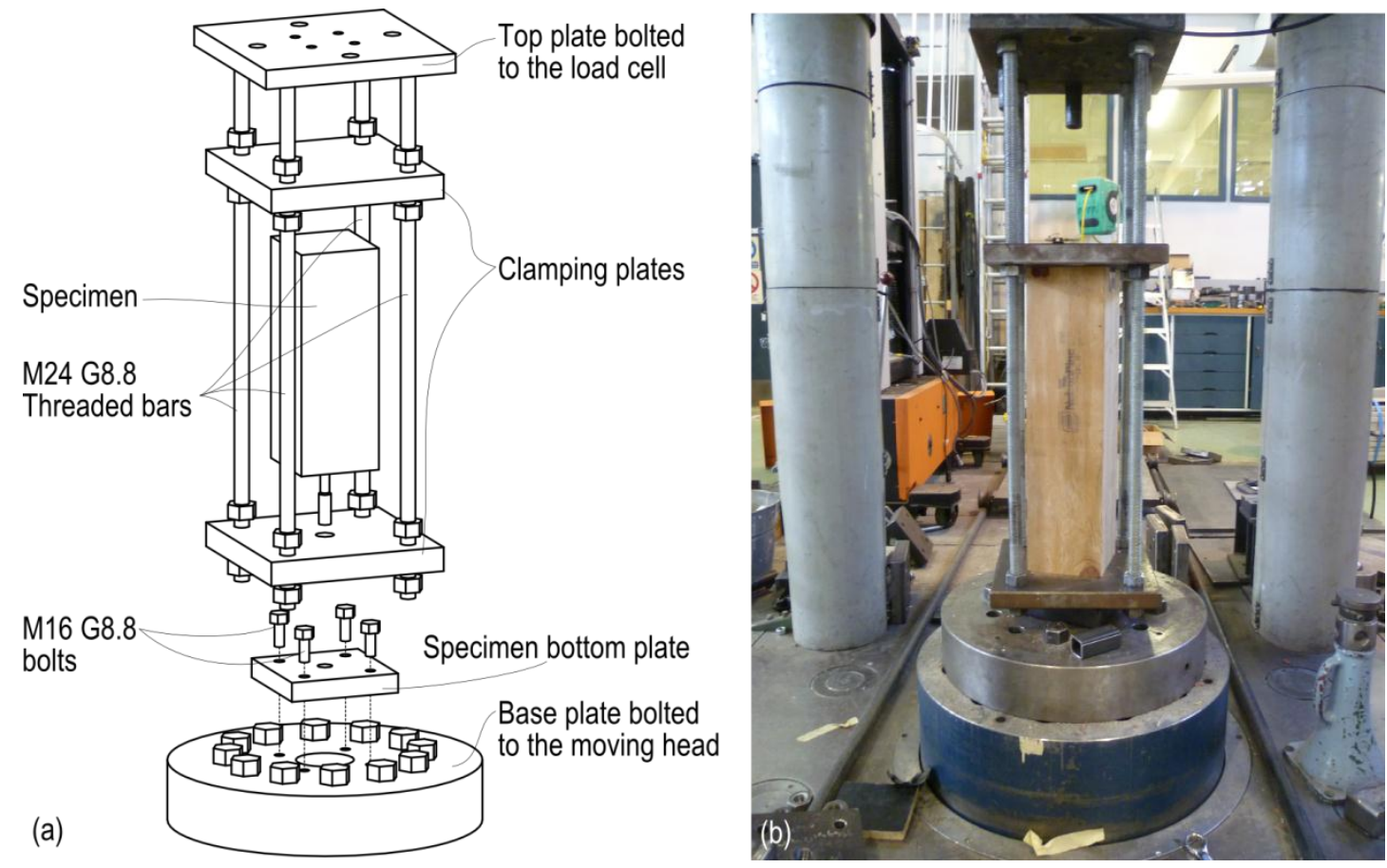

Figure 4. (a) Test setup 3D view and (b) testing machine. 


\section{Data analysis}

\subsection{Determination of the bond-stress relationship}

The first step in the experimental campaign was to determine the bond stress-slip relationship for internal bars in timber. To achieve the purpose, the specimens were designed to have a short embedment length in order to trigger the pull-out failure mechanism.
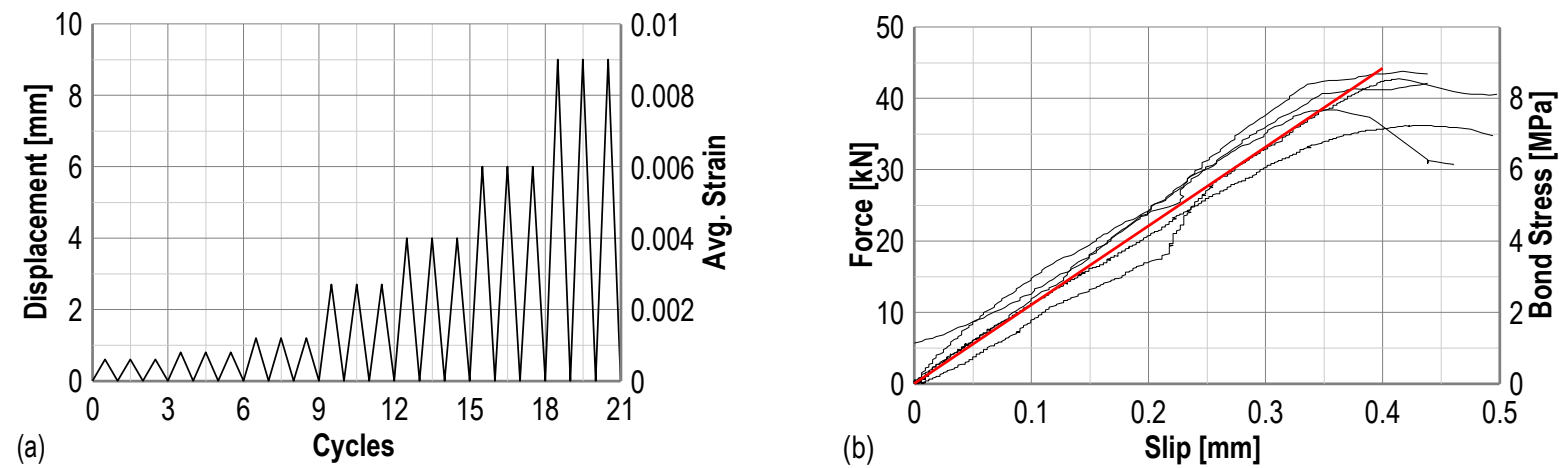

Figure 5. (a) Testing protocol. (b) Force-slip pull-out tests experimental results.

The slip, $s$, was measured at the top of the specimen, while the force recorded by the load cell was converted into the average bond stress, $\tau$, by dividing the force by the bond surface:

$$
\tau=\frac{F}{D_{h} \pi L}
$$

Where $\mathrm{F}$ is the recorded force, $\mathrm{D}_{\mathrm{h}}$ the hole diameter (see Figure 2) and $\mathrm{L}$ the specimen length.

Figure 5 shows the experimental results of the pull-out tests. The experimental force-slip charts show a brittle failure is occurring soon after the maximum bond stress is reached; therefore the bond stress-slip relationship can be approximated by a linear function.

Based on the average results of the experimental tests the bond stress-slip relationship is:

$$
\tau(s)=\frac{\tau_{\max }}{s_{1}} s
$$

Where $\tau_{\max }$ is the maximum bond stress and $\mathrm{s}_{1}$ the slip at maximum bond stress

The average maximum bond stress and slip were, respectively, $8.8 \mathrm{MPa}$ and $0.4 \mathrm{~mm}$.

\subsection{Instrumentation and data analysis}

To analyse the experimental strain data, a theoretical approach was adopted and the differential equations governing the bond behaviour were considered [12].

The instrumentation apparatus was mainly oriented into the determination of the strain profile in the bond region; therefore, in addition to the general force-displacement behaviour recorded by the testing machine multiple strain readings were recorded by the strain gauges glued on the bars as shown in Figure 3c. 
The equations used in this paper are based on the assumption of perfect elasticity for both the reinforcing steel and the timber; moreover, long member behaviour was considered. According to this assumption a portion of the anchorage is ineffective because of slip absence [12].

Assuming axial symmetry with respect to the bar axis and neglecting the radial dimension, the differential equations are summarized below. For the purposes of the experimental data analysis of this paper, the glue layer was considered to perfectly transfer the stresses and was therefore neglected.

By means of the differential equations reported below, a fitting function could be worked out and used to fit experimental data and extrapolate significant parameters such as the slip at the start of the bond region, the slip penetration and the strain penetration.

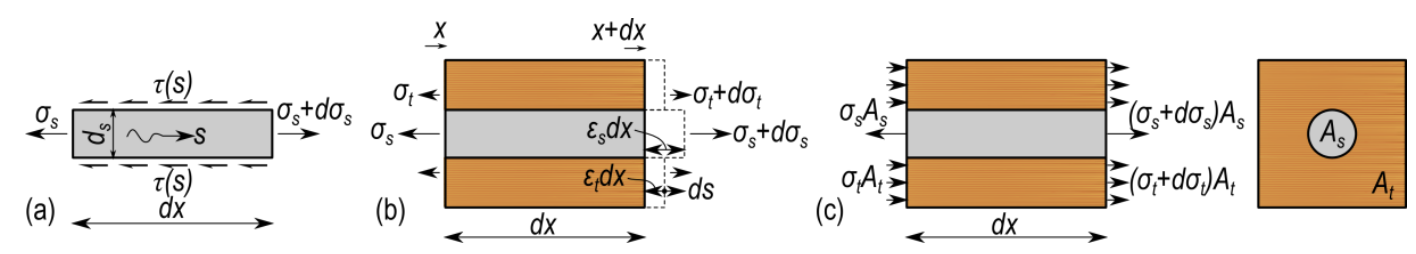

Figure 6. (a) Stresses acting on a reinforcing bars; (b)stresses in and strain in the bar in the timber block; (c) force acting on a reinforced-timber element

The equilibrium in the reinforcing bar can be defined in Equation (7) with reference to Figure 6a as:

$$
A_{s} \frac{d \sigma_{s}(x)}{d x}=-\Sigma_{0} \tau(s)
$$

Where $\mathrm{A}_{\mathrm{s}}$ is the bar section, $\Sigma_{0}$ the bar circumference, $\sigma_{\mathrm{s}}(\mathrm{s})$ the steel stress, $\tau(\mathrm{s})$ the bond stress and $\mathrm{s}$ the relative slip

Figure $6 \mathrm{~b}$ shows the stresses and strains in the bar and the timber and their difference and can be written as the strain-displacement relation of Equation (8):

$$
\varepsilon_{s}-\varepsilon_{t}=-\frac{d s(x)}{d x}
$$

Where $\varepsilon_{\mathrm{s}}$ is the steel strain and $\varepsilon_{\mathrm{t}}$ the average strain in the timber embedment.

From equilibrium (Figure 6)

$$
A_{t} \frac{d \sigma_{t}}{d x}=-A_{s} \frac{d \sigma_{s}}{d x}
$$

Where $A_{t}$ is the timber cross-section and $\sigma_{t}$ the timber stress

The derivation of (8) substituting (7) and (9) gives Equation (10).

$$
\begin{aligned}
& \frac{d^{2} s}{d x^{2}}-\chi \tau[s(x)]=0 \\
& \chi=\left(1+\frac{E_{s, t}}{E_{t}} \frac{A_{s}}{A_{t}}\right) \Sigma_{0} / A_{s} E_{s, t}
\end{aligned}
$$

Where $E_{s, t}$ is the tangential modulus of elasticity of the steel bar, $E_{t}$ the timber modulus of elasticity and $\Sigma_{0}$ the bar circumference. 
Assuming linear bond stress-slip relationship from Equation (6), Equation (10) can be re-written as follows.

$$
\frac{d^{2} s}{d x^{2}}-\chi \frac{\tau_{\max }}{s_{1}} s(x)=0
$$

The solution of Equation (12) is given in Equation (13):

$$
s(x)=c_{1} e^{\sqrt[x]{\chi_{\frac{\tau_{\text {max }}}{s_{1}}}}}+c_{2} e^{-x \sqrt{\chi^{\frac{\tau_{\text {max }}}{s_{1}}}}}
$$

Where $c_{1}$ and $c_{2}$ are integration constants and $\mathrm{x}$ the abscissa along the bar bond region.

Equation (8) can also be written deriving Equation (13):

$$
\varepsilon_{s}-\varepsilon_{t}=\sqrt{\chi \frac{\tau_{\max }}{s_{1}}}\left(c_{1} e^{\sqrt[x]{\chi^{\frac{\tau_{\text {max }}}{s_{1}}}}}-c_{2} e^{-x \sqrt{\frac{\tau_{\text {max }}}{s_{1}}}}\right)
$$

Figure 7 shows the analysis framework for the calibration of the equivalent strain penetration length. The recorded strain points at each loading step were fitted using Equation (14) which allowed the calibration of the integration constants. This was then substituted into Equation (13), and the slip due to strain and the slip at the base of the bond region $(\mathrm{x}=0)$ was determined.

The slip, $\mathrm{s}(\mathrm{x}=0)$, was then plotted versus the maximum strain at the same point; this experimental plot was then fitted with a bi-linear curve and the slope of the elastic portion of this curve represented the equivalent strain penetration length.

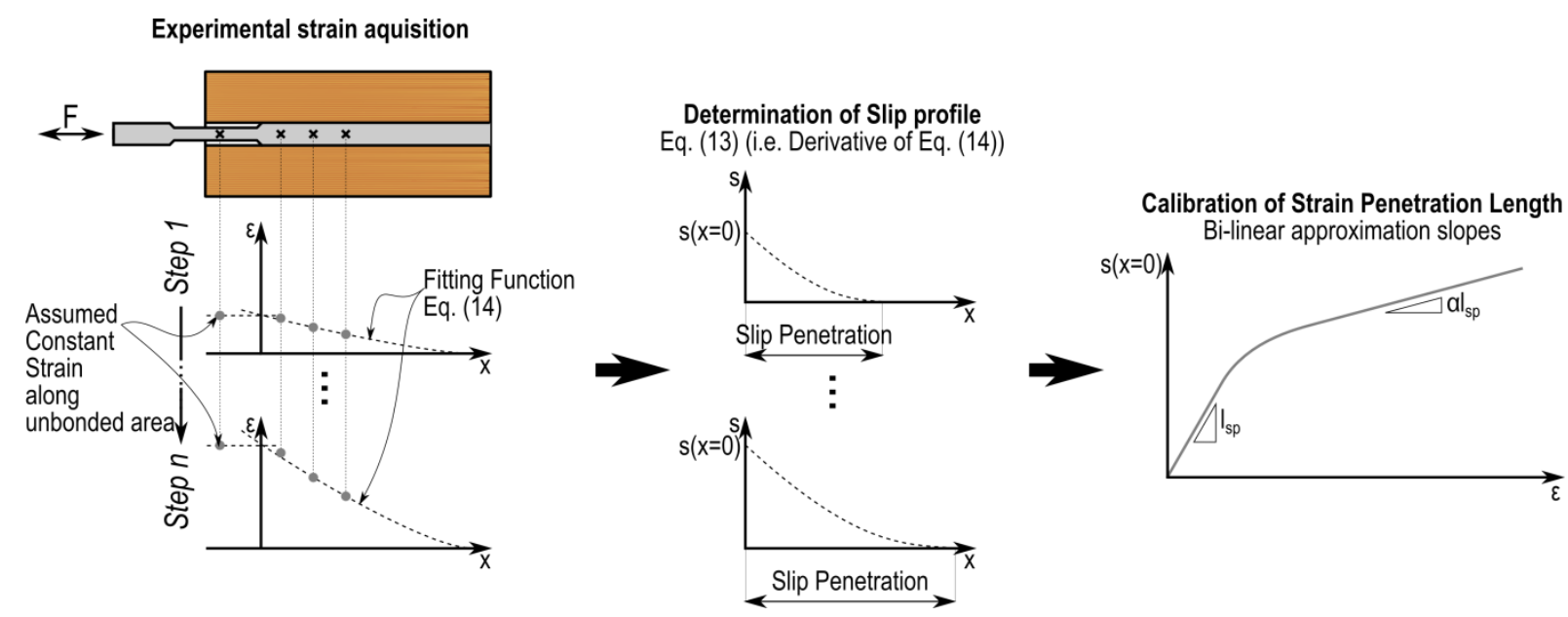

Figure 7. Data Analysis flow chart.

\section{Results}

Figure 8 shows the experimental monotonic results for the specimens SP16t, SP20t and SP24t in terms of force-displacement; strain along the embedment length, slip penetration and total slip, also plotted versus the maximum strain measured externally in the fused portion of the bar. 


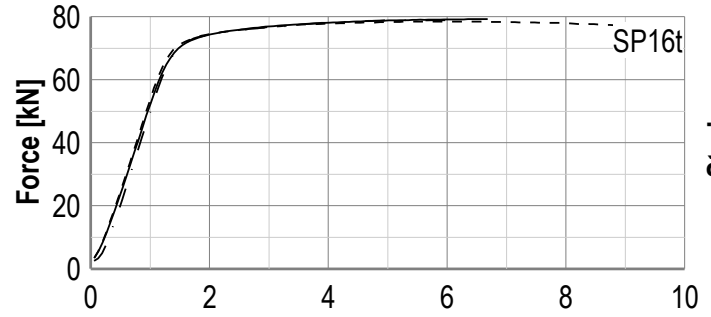

(a)

Displacement [mm]

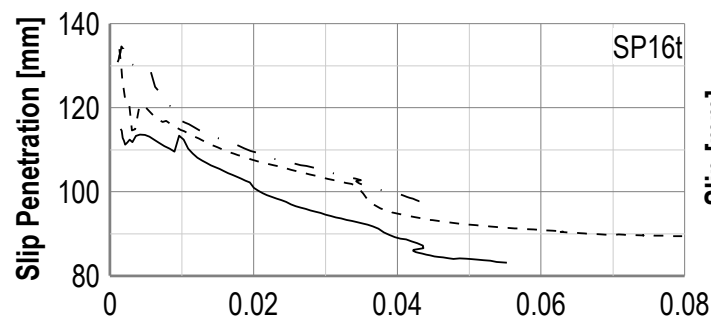

(c)

Bar Max. Strain

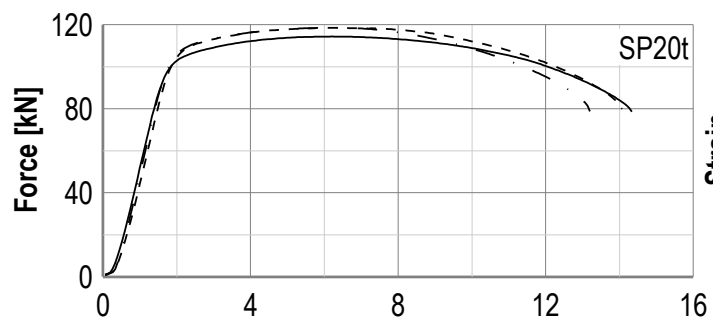

(a)

Displacement [mm]

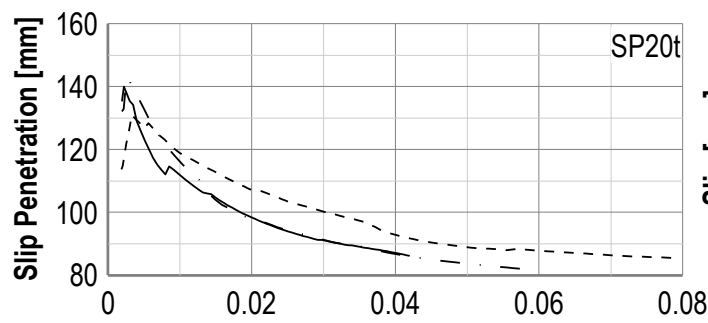

(c)

Bar Max. Strain

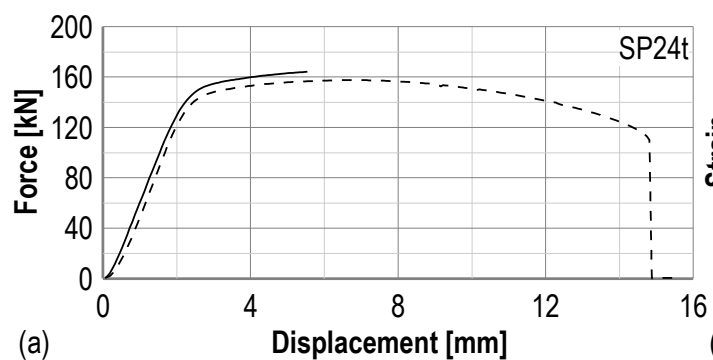

(a)

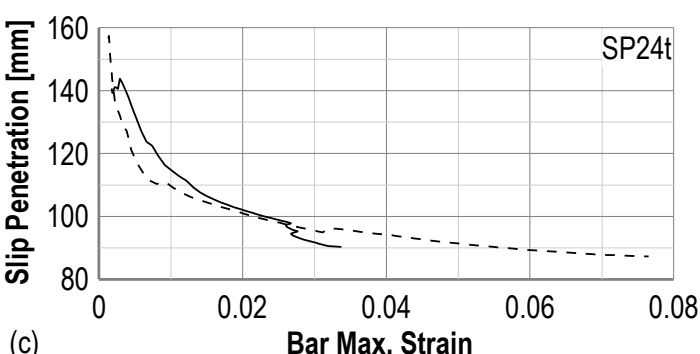

(c)

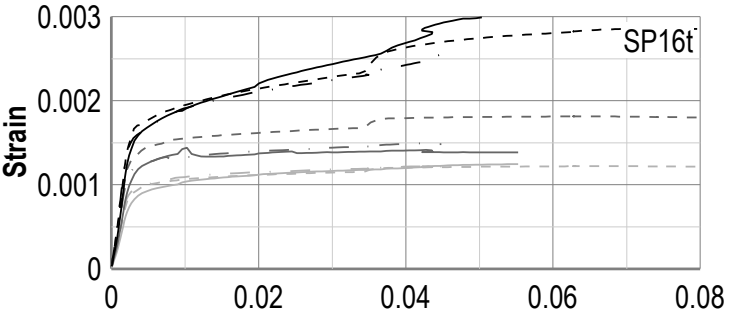

(b)

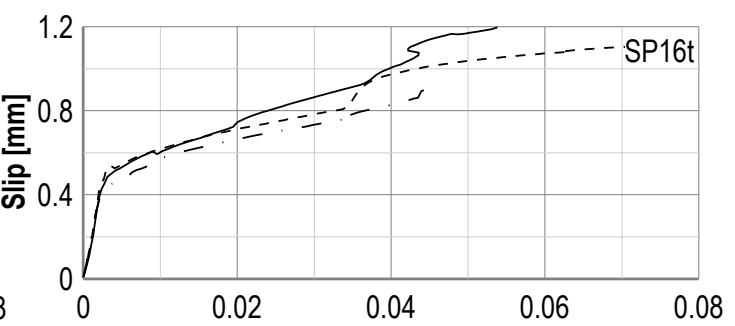

(d)

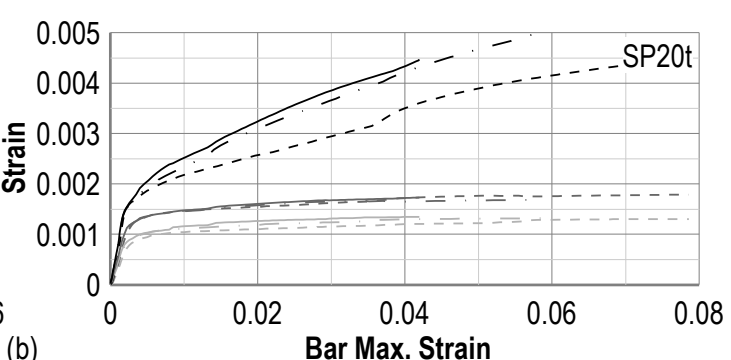

(b)

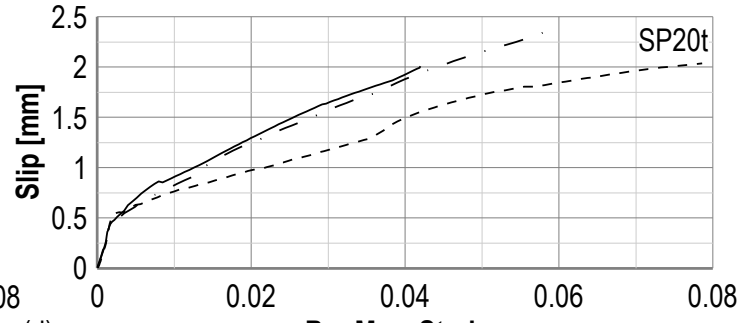

(d)

Bar Max. Strain

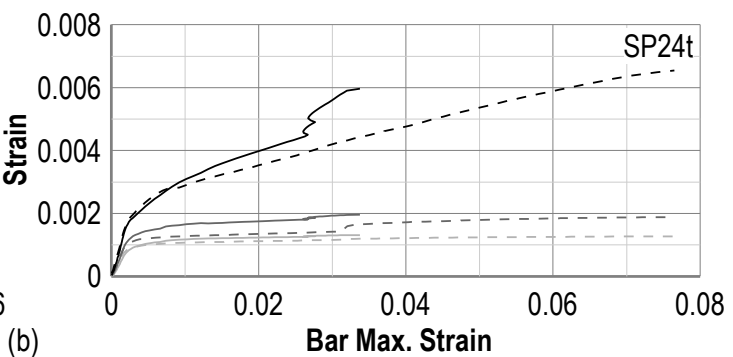

(b)

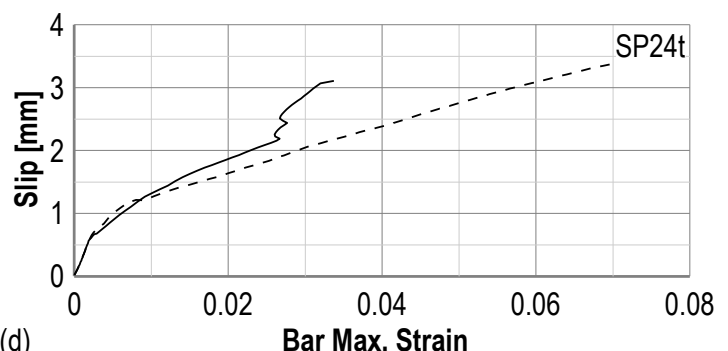

(d)

Figure 8. Experimental monotonic results, threaded bars: (a-d) SP16t; (e-h) SP2Ot; (i-l) SP24t; 
As expected from hardened steel Grade 4.6 the bar force-displacement did not show any yielding plateau typical of mild steel Grade 300 and 500. The strain measurements were consistent for the three specimens tested. From a more detailed observation of the variation of the strain in the embedment length, it can be observed that the deeper strain gauges recorded nearly constant strains after yielding, when most of the strain is concentrated in the yielding section external of the timber block. This is also consistent with the observed trend of the slip penetration (Figure 8c). The latter is defined as the zero of the slip function (Equation (13)), i.e. the abscissa indicating the equivalence of the timber and steel strains.

The behaviour in terms of strain distribution along the bond region for deformed bars (Figure 9b, f) showed a slight difference. Some strain increase was observed also beyond yield. This is confirmed by the constant trend of the slip penetration (Figure 9c, g).
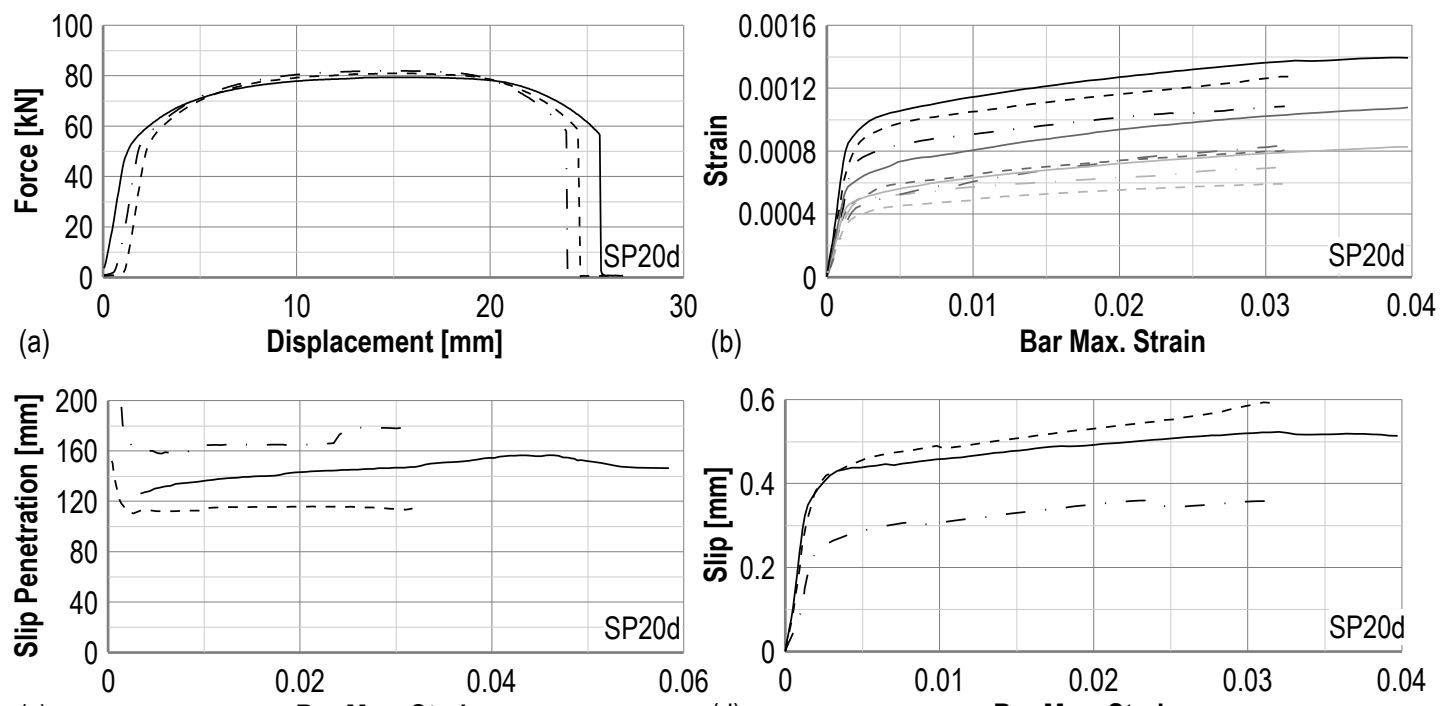

(c)

Bar Max. Strain

(d)
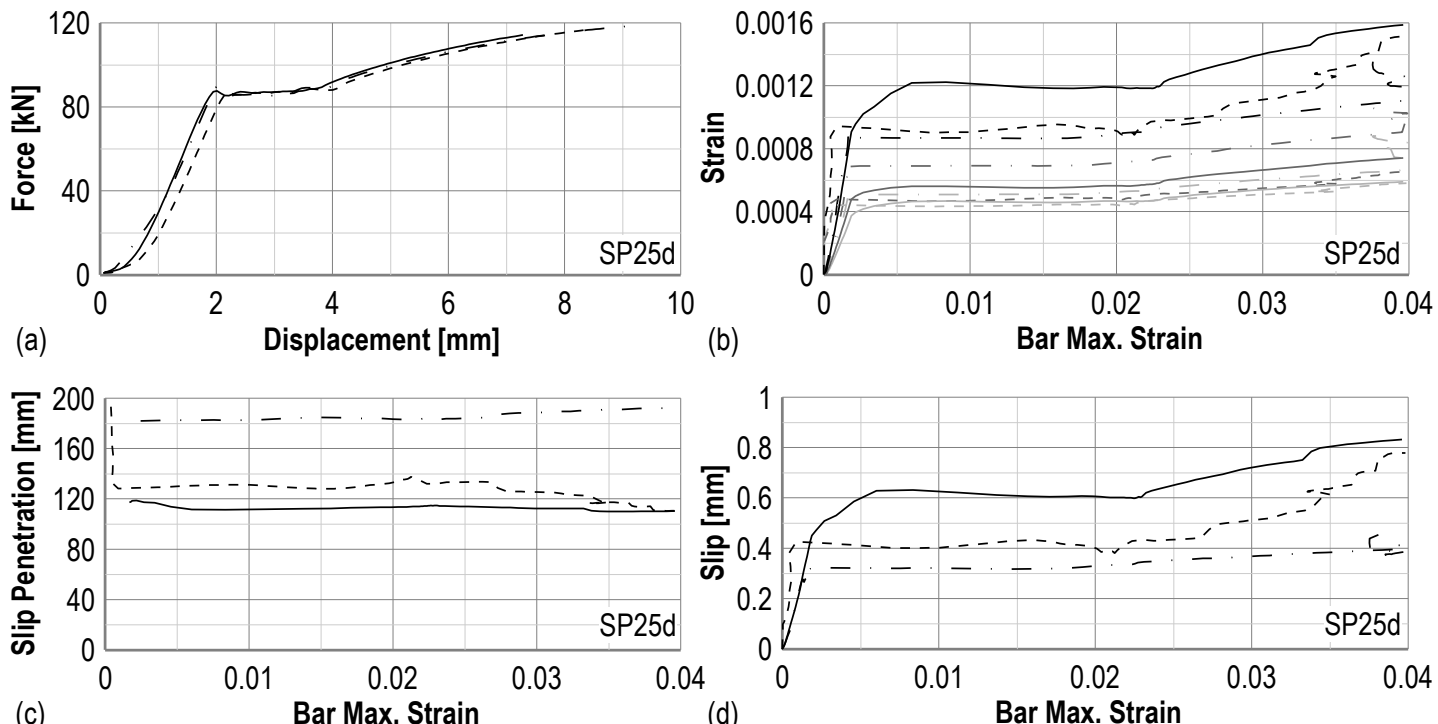

(c)

Bar Max. Strain

(d)

Bar Max. Strain

Figure 9. Experimental data monotonic results, deformed bars: (a-d) SP20d; (e-h) SP25d 
The proposed analytical model was calibrated using the slip values extrapolated from experimental. The experimental values of Figure 8 are plotted against the bar maximum strain at the start of the bond length and it shows a bilinear trend for all the specimens.

A similar behaviour was observed for deformed bars, but the strain readings (Figure $9 \mathrm{~b}, \mathrm{f}$ ) in the bond region tended to increase even when plastic maximum strain was developed in the fused portion of the bar. This was also confirmed by the evaluated slip penetration (Figure 9c, g), which shows a constant trend.

The specimens were also tested cyclically to assess whether any degradation in the behaviour was occurring and Figure 10 summarizes the results of the specimens SP16t and SP20d in terms of slip versus maximum strain in the bar. Experimental results on cyclic testing shows no degradation (i.e. cyclic increase of bar slip) occurred; therefore, the monotonic test results were used in the following paragraph to work out the proposed analytical model for strain penetration in internally glued bars.
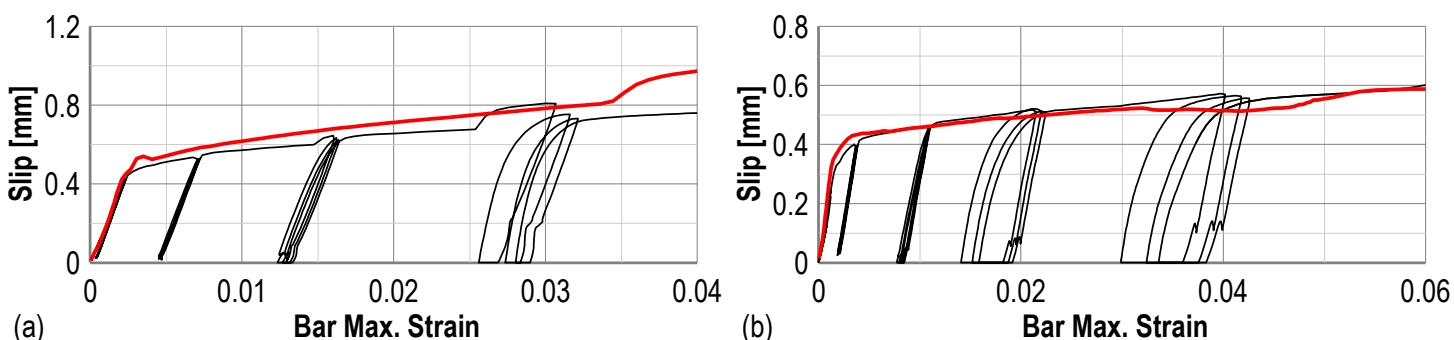

Figure 10. Experimental data cyclic results: (a) SP16d; (b) SP20d

\section{Proposed analytical model}

The proposed model is defined in terms of additional slip due to strain penetration, $\Delta_{\mathrm{sp}}$. This contribution can be consistently defined as a function of the maximum strain measured at the start of the bonded length. A bilinear relationship was observed, so the slip due strain penetration, $\Delta_{\mathrm{sp}}$, is defined as:

$$
\Delta_{s p}=l_{s p} \varepsilon_{e}+\alpha l_{s p} \varepsilon_{p}
$$

Where $1_{\mathrm{sp}}$ is the strain penetration length, $\varepsilon_{\mathrm{e}}, \varepsilon_{\mathrm{p}}$ the elastic and plastic strains, $\alpha$ the post-yielding slip factor.

As proposed in past research, the strain penetration length is expressed as a function of the yield strength and diameter of the bar; the experimental results in terms of slip-maximum strain were normalized accordingly.

Figure 11 shows the normalized slip results of the threaded and deformed bars specimens. The experimental test data shows consistent results of the slip in the elastic range of strain, yet a significant difference in the slope is evident for plastic deformations. From averaging the experimental results (Figure 11 red solid plot) a bi-linear approximation was used and the slopes of the two branches give the calibrated values.

Therefore, the strain penetration length parameters for internal bars are given below: 


$$
l_{s p}=0.032 f_{y} d_{b}, \alpha=\left\{\begin{array}{lr}
0.094 & \text { threaded } \\
0.031 & \text { deformed }
\end{array}\right.
$$
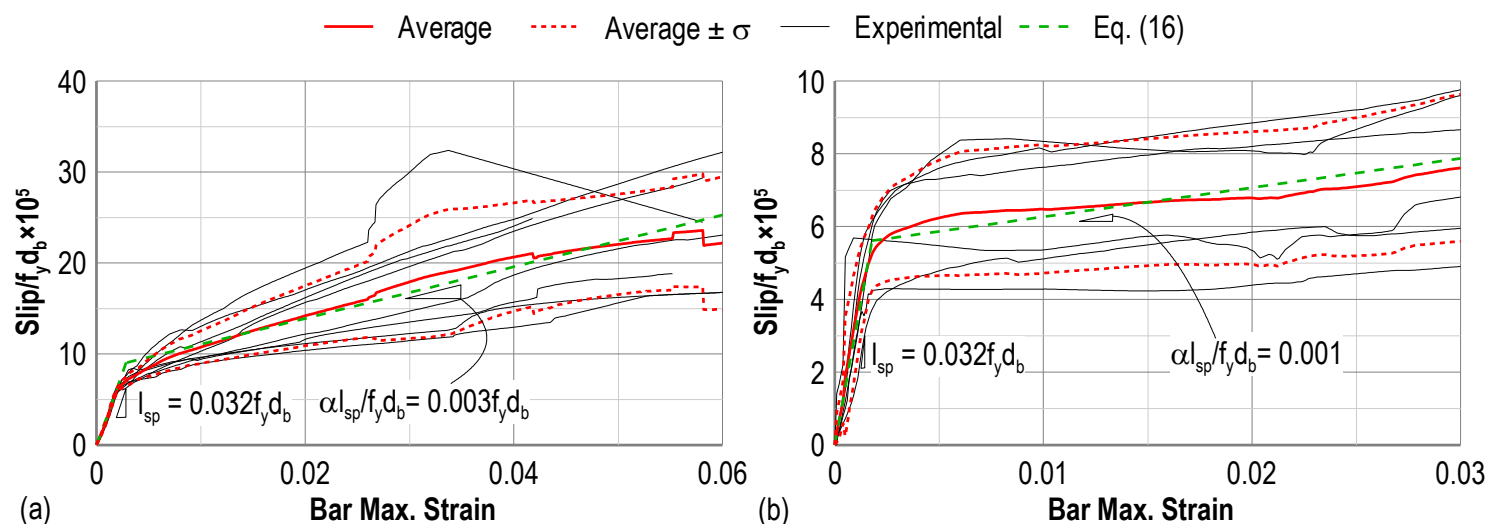

Figure 11. Normalized slip and strain penetration length formulation for (a) threaded and (b) deformed bars

\section{Significance to connection design}

Tensile strain penetration effect can have a significant influence in the behaviour of timber connections using epoxied steel bars.

This section focusses on a design example of a post-tensioned rocking wall-foundation connection. In this type of connection internal epoxied bars provide dissipation, and they are used in the form of starter bars.

As proposed by Pampanin et al. [13] as well as Palermo and Pampanin [14] the design and analysis of an unbonded post-tensioned element (beam-column joint, wall or bridge elements) can be carried out in following an iterative step-by-step moment-rotation procedure, referred to as Monolithic Beam Analogy. The procedure relies on a global strain compatibility condition by assuming that the displacement of a post-tensioned connection is equal to that of an equivalently reinforced concrete monolithic connection.

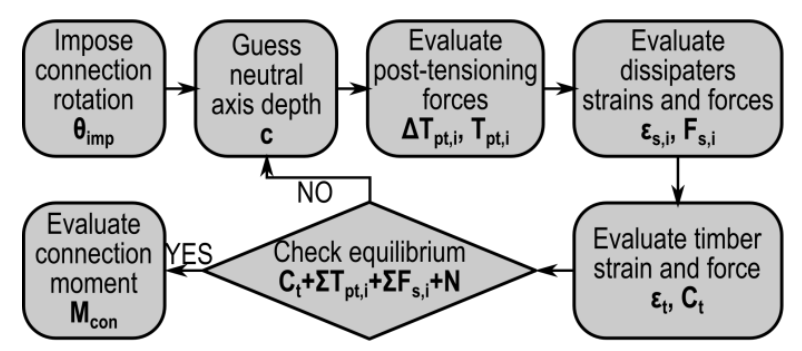

(a)

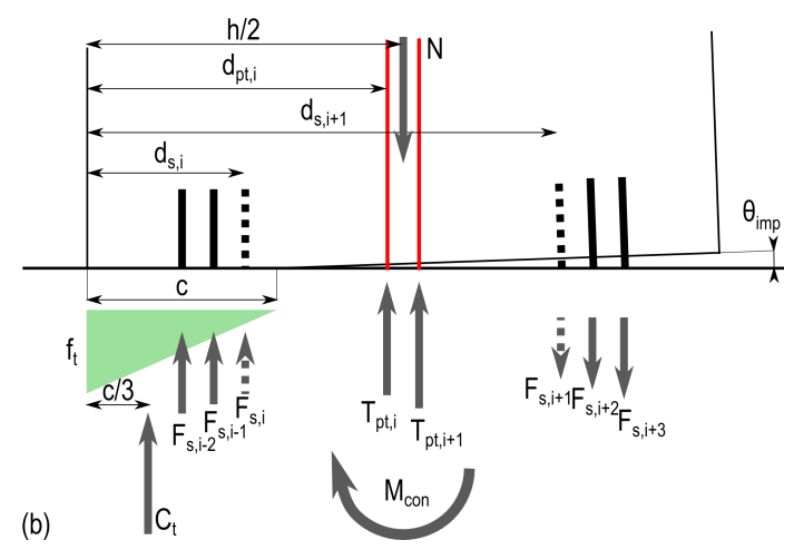

Figure 12. (a) Monolithic Beam Analogy moment-rotation procedure. (b) Connection rocking mechanism and nomenclature.

The iterative moment-rotation procedure, referred to as Modified Monolithic Beam Analogy (MMBA) was later extended and applied to dissipative post-tensioned timber elements by Newcombe et al. [7], and 
that is summarized in the flowchart in Figure 12a and briefly presented below (nomenclature is reported in Figure 12b).

The procedure's first step consists of imposing the connection rotation, $\theta_{\text {imp }}$, and guessing the neutral axis depth.

For the imposed rotation, $\theta_{\text {imp }}$, and guessed neutral axis depth, c, the strain and force of the i-th posttensioning layer is then evaluated as:

$T_{p t, i}=T_{p t 0, i}+\Delta T_{p t, i}=T_{p t 0, i}+\frac{\Delta_{p t, i}}{l_{u b}} E_{p t} A_{p t, i}, \Delta \varepsilon_{p t, i}=\frac{\Delta_{p t, i}}{l_{u b}}=\frac{\theta_{i m p}\left(d_{p t, i}-c\right)}{l_{u b}}$

Where $\Delta_{\mathrm{pt}, \mathrm{i}}$ the elongation of the $\mathrm{i}$-th post-tensioning reinforcement layer, $\mathrm{d}_{\mathrm{pt}, \mathrm{i}}$ the edge distance of the $\mathrm{i}$-th post-tensioning reinforcement layer, $1_{\mathrm{ub}}$ the unbonded length of the $\mathrm{i}$-th post-tensioning reinforcement layer, $\mathrm{E}_{\mathrm{pt}}$ the post-tensioning steel elastic modulus, $\mathrm{A}_{\mathrm{pt}, \mathrm{i}}$ the cross-section area of the $\mathrm{i}$-th post-tensioning reinforcement layer, $\mathrm{T}_{\mathrm{pt} 0 \mathrm{i}}$ the initial post-tensioning force of the $\mathrm{i}$-th post-tensioning reinforcement layer Then, the strain in partially unbonded internal bars can be evaluated.

An alternative configuration can be adopted using internal fused bars. The additional displacement for this reinforcement option is given by the strain penetration contribution from Equation (15). When the bar is also embedded in concrete, the contribution proposed by Sritharan [2] (see Equation (1)) shall be taken into account as well. The strain in the internal dissipater is evaluated below:

$$
\begin{aligned}
& \varepsilon_{s, i}=\frac{\Delta_{s, i}-\Delta_{s p, i}}{l_{u b}^{\prime}} \\
& \Delta_{s p, i}=\Delta_{s p, c o n c r e t e}+\Delta_{s p, t i m b e r}=0.022 f_{s y} d_{b}\left(\frac{2}{3} \varepsilon_{e, i}+\varepsilon_{p, i}\right)+0.032 f_{s y} d_{b}\left\{\begin{array}{l}
\left(\begin{array}{l}
\left(\varepsilon_{e, i}+0.094 \varepsilon_{p, i}\right) \\
\left(\varepsilon_{e, i}+0.031 \varepsilon_{p, i}\right)
\end{array}\right. \text { deformed }
\end{array}\right.
\end{aligned}
$$

Where $\mathrm{f}_{\mathrm{sy}}$ is the mild steel yield strength, $\mathrm{D}_{\text {fuse }}$ the fuse diameter of the dissipater, $\varepsilon_{\mathrm{e}, \mathrm{i}}$ the elastic strain in the $\mathrm{i}$-th dissipative layer, $\varepsilon_{\mathrm{p}, \mathrm{i}}$ the elastic strain in the $\mathrm{i}$-th dissipative layer.

The dissipater force, $\mathrm{F}_{\mathrm{s}, \mathrm{i}}$, can then be evaluated assuming a bi-linear stress-strain relationship.

$F_{s, i}=A_{s, i} f_{y s}\left[1+r\left(\frac{\varepsilon_{s, i}}{\varepsilon_{y s}}-1\right)\right]$

To evaluate the timber strain according to the MMBA [7], $\varepsilon_{\mathrm{t}}$, the strain compatibility condition is applied, and the displacement of the rocking element is assumed to be the same as that of the analogic monolithic element.

The timber force is evaluated assuming a triangular stress distribution:

$$
C_{t}=0.5 E_{c o n} \varepsilon_{t} b c, \varepsilon_{t}=c\left(\frac{3 \theta_{i m p}}{L_{c a n t}}+\phi_{d e c}\right)
$$

Where $\phi_{d e c}=M_{d e c} / E_{c o n} I$ is the decompression curvature, $\mathrm{E}_{\text {con }}$ the connection modulus (equal to $0.7 \mathrm{E}_{\mathrm{t}}$ for post-tensioned timber walls), $\mathrm{E}_{\mathrm{t}}$ the timber modulus of elasticity, I the section second moment of area, $\mathrm{L}_{\text {cant }}$ the cantilever length, $\mathrm{b}$ the section width

Once the force contributions are evaluated, the force equilibrium must be assessed. 
$-C_{t}+\sum_{i=1}^{n_{s}} F_{s, i}+\sum_{i=1}^{n_{p t}} T_{p t, i}=-N$

If the equilibrium is not satisfied the neutral axis depth value must be iterated, otherwise the connection moment can be evaluated around the timber compression centroid.

$M_{c o n}=\sum_{i=1}^{n_{p t}} T_{p t, i}\left(d_{p t, i}-\frac{c}{3}\right)+\sum_{i=1}^{n_{s}} F_{s, i}\left(d_{s, i}-\frac{c}{3}\right)+N\left(\frac{h}{2}-\frac{c}{3}\right)$

Where $\mathrm{h}$ is the section depth

The evaluation of the correct strain in the dissipation devices is considered a crucial evaluation for a correct estimation of the ductility of the section. In fact, if the strain penetration effect is neglected the strain is over-estimated. This may be a conservative assumption for the design of the internal dissipater to prevent premature fracture, yet this over-estimation leads to an un-conservative evaluation of the section ductility.

\subsection{Section analysis example}

This last section of the paper briefly discusses the section analysis of a dissipative post-tensioned timber section focusing in particular on the significance of the strain penetration effects on the evaluation of the main design parameters of the section.

The rectangular section shown in Figure 13 was used for the example. The section is $1.2 \mathrm{~m} \times 90 \mathrm{~mm}$ and that can be representative of a small post-tensioned timber wall. The post-tensioning reinforcement is a $25 \mathrm{~mm}$ diameter MacAlloy steel bar [15] and its initial post-tensioning load is $250 \mathrm{kN}$. Internal mild steel bars provide the dissipation to the system and those are 4 Grade $30020 \mathrm{~mm}$ reinforcing mild steel bars which were machined to a reduced diameter of $16 \mathrm{~mm}$.
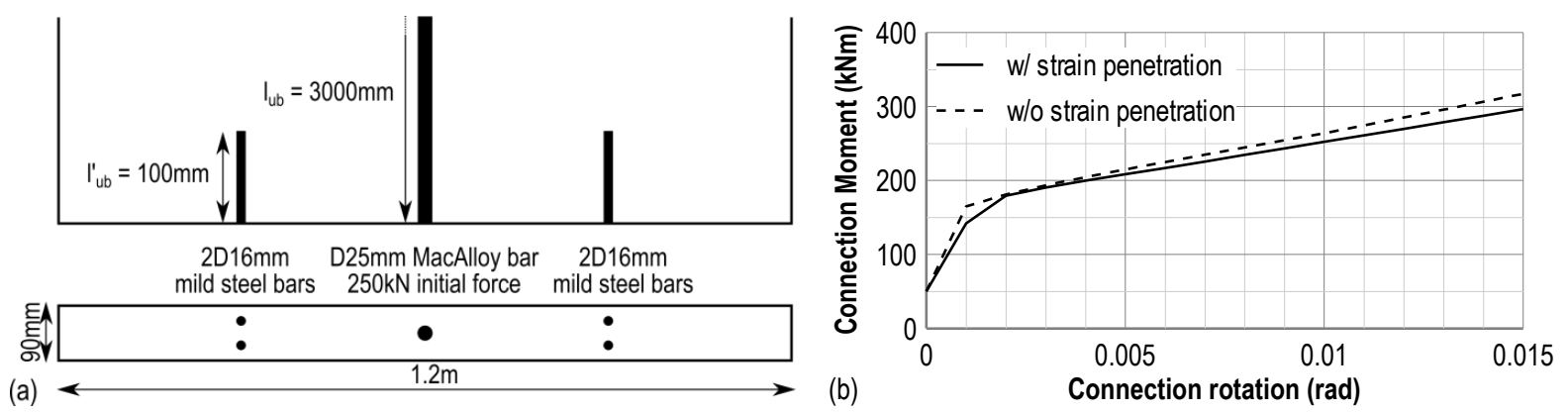

Figure 13. (a) Section geometry. (b) Moment-rotation results.

The wall was designed to carry $1 / 4$ of the horizontal loading of a single storey building of total seismic weight $680 \mathrm{kN}$ (i.e. four resisting walls are considered). The building is considered to be located in Christchurch $(Z=0.3)$ on a soil type $D$. The design was carried out in accordance to NZS1170.5 [16] with a return period of 500 years $(R=1.0)$, ductility factor $\mu=3.0$ and $T_{1}<0.5 \mathrm{~s}$.

The resulting base shear and moment are $57.5 \mathrm{kN}$ and $230 \mathrm{kNm}$ at Ultimate Limit State. An additional limit state was considered in the analysis (Maximum Credible Event) and the MCE demand was 
considered to be 1.5 times the ULS demand. MCE base shear and moment are $86.2 \mathrm{kN}$ and $345 \mathrm{kNm}$ respectively.

The section analysis was carried out in accordance to the step-by-step procedure mentioned at the beginning of the paper $[7,14]$ and the results are shown and discussed in this section both considering and neglecting strain penetration effects.

The analysis results are shown in Figure 13b, and Table 3 shows the results in terms of predicted wall drift $(\Delta)$, ductility $(\mu)$, dissipater strain $\left(\varepsilon_{\mathrm{s}}\right)$, neutral axis $(\mathrm{c})$ and section moment capacity $\left(\mathrm{M}_{\mathrm{tot}}\right)$ for several limit states and rotation ductility.

Table 3. Section analysis results summary.

\begin{tabular}{l|l|l|l|l|l} 
Limit state & $\begin{array}{l}\text { Wall drift } \\
(\%)\end{array}$ & $\begin{array}{l}\text { Ductility } \\
\mu\end{array}$ & $\begin{array}{l}\text { Steel strain } \\
\varepsilon_{\mathrm{s}} \\
(\%)\end{array}$ & $\begin{array}{l}\text { Neutral axis } \\
\mathrm{c} \\
(\mathrm{mm})\end{array}$ & $\begin{array}{l}\text { Moment capacity } \\
\mathrm{M}_{\text {tot }} \\
(\mathrm{kNm})\end{array}$ \\
\hline Yield & $0.25(0.18)$ & $1.00(1.00)$ & $0.15(0.15)$ & $620(834)$ & $172(165)$ \\
\hline ULS & $0.75(0.65)$ & $3.70(4.21)$ & $1.67(3.52)$ & $344(360)$ & $230(230)$ \\
\hline MCE & $2.34(2.03)$ & $9.21(10.10)$ & $4.98(10.38)$ & $293(302)$ & $345(345)$ \\
\hline
\end{tabular}

The results in Table 3 show the parameter values with and without considering the strain penetration effects providing a comparison.

As expected, neglecting strain penetration effects results in the under-estimation of the yielding drift; therefore, the ductility is un-conservatively over-predicted at both ULS and MCE demand level.

From the comparison of strain values it can be observed that the strain penetration is fundamental for the evaluation of post-tensioned timber systems and that it can involve a significant error (as large as $100 \%)$.

While those parameters are significantly affected by strain penetration effects, drift and neutral axis depth values are not significantly influenced. Neglecting strain penetration effects resulted in a small under-estimation of the wall drift.

\section{Conclusions}

The paper presented the results of an experimental programme carried out to quantify the tensile strain penetration effects occurring in internally glued bars in timber.

The most significant parameter, the strain penetration length $1_{\mathrm{sp}}$, was determined considering different geometries and steel grades. In particular, threaded (Grade 4.6) and deformed bars (Grade 300E) were used in different diameters $(16,20$, and $24 / 25 \mathrm{~mm}$, the latter for either threaded or deformed bars).

A key design parameter when designing internal dissipative reinforcement in dissipative posttensioned rocking sections is the strain penetration length, $1_{\mathrm{sp}}$, which was defined as the elastic slope of $\Delta_{\mathrm{sp}}$ versus the bar strain. A value of $0.031 \mathrm{f}_{\mathrm{y}} \mathrm{d}_{\mathrm{b}}$ was proposed, which is similar to what used for reinforcing steel embedded in concrete elements..

The final part of the paper showed a section analysis example to highlight the influence of strain penetration effects on significant design parameters. Neglecting of strain penetration effects resulted in 
significant over-estimation of ductility and dissipater strain, but a small over-estimation (less than 2-3\%) of the drift and of the moment capacity at several limit states.

\section{Acknowledgements}

This research was funded by the Structural Timber Innovation Company (STIC). The technical support of Mr. John Maley is gratefully acknowledged.

\section{References}

1. Paulay, T. and M.J.N. Priestley, Seismic design of reinforced concrete and masonry buildings. 1992, New York: Wiley. 1 online resource.

2. Sritharan, S., Analysis of concrete bridge joints subjected to seismic actions. 1998: University of California, San Diego.

3. Priestley, M.J.N., G.M. Calvi, and M.J. Kowalsky, Displacement-based seismic design of structures. 2007, Pavia, Italy: IUSS Press.

4. Priestley, M.J.N., Overview of PRESSS research program. PCI Journal, 1991. 36(4): p. 50-57.

5. Christopoulos, C., A. Filiatrault, C.M. Uang, and B. Folz, Post-tensioned Energy Dissipating Connections for Moment Resisting Steel Frames. Journal of Structural Engineering, 2002. 128(9): p. 1111-1120.

6. Palermo, A., S. Pampanin, A.H. Buchanan, and M.P. Newcombe. Seismic design of multi-storey buildings using laminated veneer lumber (LVL). in New Zealand Society of Earthquake Engineering, Annual Conference. 2005. Wairakei, New Zealand: University of Canterbury. Civil Engineering.

7. Newcombe, M.P., S. Pampanin, A.H. Buchanan, and A. Palermo, Section Analysis and Cyclic Behavior of Post-Tensioned Jointed Ductile Connections for Multi-Story Timber Buildings. Journal of Earthquake Engineering, 2008. 12(S1): p. 83-110.

8. Buchanan, A.H. and R.H. Fairweather, Design of Glulam Structures. Bulletin of the New Zeland Natoinal Society for Eartquake Engineering, 1993. 26(4): p. 415-436.

9. Buchanan, A., P. Moss, and N. Wong, Ductile moment-resisting connections in glulam beams, in New Zealand Society of Earthquake Engineering, Annual Conference. 2001: Taupo, New Zealand.

10.Buchanan, A.H., Timber design guide. 3rd ed. 2007, Wellington, New Zealand: New Zealand Timber Industry Federation.

11.ACI Innovation Task Group 5, Acceptance criteria for special unbonded post-tensioned precast structural walls based on validation testing and commentary : an ACI standard. ITG-5.1-07. 2008, Farmington Hills, Mich.: American Concrete Institute.

12.Fédération internationale du béton, Bond of Reinforcement in Concrete: State-of-art Report, in Bulletin. State-of-art report, 10. 2000, International Federation for Structural Concrete.

13.Pampanin, S., M.J.N. Priestley, and S. Sritharan, Analytical modelling of the seicmic behaviour of precast concrete frames designed with ductile connections. Journal of Earthquake Engineering, 2001. 5(3): p. 329-367. 
14.Palermo, A. and S. Pampanin, Analysis and simplified design of precast jointed ductile connections, in World Conference on Earthquake Engineering. 2008: Beijing, China.

15.Macalloy, European Technical Approval ETA-07/0046, in ETA-07/0046, European Organization for Technical Approvals, Editor. 2007: Charlottenlund, Denmark. p. 84.

16.Standards New Zealand, NZS 1170.5: Structural Design Actions - Part 5: Earthquake actions. 2004. 